\title{
Synthesis of New Series of Pyrazoline, and Study their Kinetics and Reaction Mechanism
}

\author{
Kosrat N. Kaka, Salam G. Taher, Wali M. Hamad and Aram H. Ibrahim \\ Department of Chemistry, Faculty of Science and Health, Koya University, \\ Koya KOY45, Kurdistan Region - F.R. Iraq
}

\begin{abstract}
A new series of novel pyrazoline compounds were synthesized by addition of thiosemicarbazide to the 2,6-dibenzylidenecyclohexanone (Chalcone) and its parasubstituted derivatives. This study was conducted for four purposes. First, a series of five-membered ring pyrazoline compounds were synthesized, and the structure of all new products obtained is supported by spectral data $\left({ }^{1} \mathrm{H}-\mathrm{NMR},{ }^{13} \mathrm{CNMR}\right.$, infrared, and ultraviolet [UV]-visible), and the effect of substituents was studied. Second, the reaction kinetics of the newly synthesized compounds was studied to investigate the reaction mechanism pathway and order of the reaction; it was found that the reaction undergoes through Claisen route of mechanism with first-order reaction. Third, the thermodynamics of the reaction were studied, the rate of the reaction, Arrhenius parameters (A), and thermodynamic parameters for activation includes free energies $\left(E_{\mathrm{a}}\right)$, entropies $\left(\Delta S^{\#}\right)$, and Gibbs free energy $\left(\Delta G^{\#}\right)$ were estimated. Finally, the compensation effect was also studied and found the same pathway for all of the synthesized pyrazoline compounds.
\end{abstract}

Index Terms-Pyrazolines, Kinetics, Mechanism, Chalcones, Compensation effect, Thiosemicarbazide, Claisen and Michael Pathway.

\section{INTRODUCTION}

Nucleophilic addition to $\alpha, \beta$-unsaturated carbonyl compound as aldehydes, ketones carboxylic acids, and esters is one of the common reactions in organic synthesis. The presence of two conjugated functional groups $\mathrm{C}=\mathrm{C}$ and $\mathrm{C}=\mathrm{O}$ in the structure of $\alpha, \beta$-unsaturated carbonyl compounds ease the nucleophilic addition reaction to occur frequently (Esmaeel, 1988). Moreover, $\alpha, \beta$-unsaturated enones are important intermediate in many addition reactions of nucleophiles due to inductive polarization of carbonyl group at the $\beta$ position (Ebenezer and Wight, 1995, Hamad et al., 2016). Furthermore, electrophilic addition (McCrae, 1973), Claisen

ARO-The Scientific Journal of Koya University Volume VII, No.2(2019), Article ID: ARO.10508, 9 pages DOI: $10.14500 /$ aro. 10508

Received 06 March 2019; Accepted: 18 August 2019

Regular research paper: Published 10 December 2019

Corresponding author's e-mail: Kosrat.nazad@koyauniversity.org Copyright (C) 2019 Kosrat N. Kaka, Salam G. Taher, Wali M. Hamad and Aram H. Ibrahim. This is an open-access article distributed under the Creative Commons Attribution License. addition (Carey, 1996), and Michael addition (Gutsche, 1967) are the most known types of such kind of reactions, and the use of heterocyclic compounds is the most common, due to their interesting biological activities.

Pyrazoline is a heterocyclic compound that contains two adjacent nitrogen atoms; it can be synthesized using variety of methods. Pyrazoline compounds are not stable; readily convert to cyclopropane derivatives in the presence of heat or base catalyst (Qiu et al., 2008; Ramage et al., 1957). Pyrazoline and its derivatives are important compounds which constitute the basic framework of certain drug (Patel et al., 2011); also they are important precursors for pharmaceuticals and pesticides (Sloop et al., 2008).

Pyrazoline compounds show a variety of biological activates such as anticonvulsant (Beyhan et al., 2017), antimicrobial (Joshi et al., 2012, Pandya et al., 2017, Kendre and Baseer, 2013, Hassan, 2011) antituberculosis, antileishmanial (Monga et al., 2014), and antifungal properties (Hassan, 2011).

There are several works that have been published for the synthesis of pyrazolines. Mainly, the pyrazoline synthesis is based on the cyclization reaction of different chalcones with hydrazine compounds (Li et al., 2007, Lévai, 2005, Powers et al., 1998, Joshi et al., 2012, Pandya et al., 2017, Monga et al., 2014, Ethiraj et al., 2013, Kendre and Baseer, 2013, Hassan, 2011, Fazaeli et al., 2010), as shown in Scheme 1.

Beyhan et al. reported a different method for the synthesis of pyrazoline compounds from the reaction of chalcones (prepared from methyl aryl ketones with substituted aldehydes) with thiosemicarbazide and N-(4-chlorophenyl) semicarbazide in alkaline medium (Beyhan et al., 2017). Another method for the synthesis of pyrazoline is through the reaction of substituted hydrazonoyl and N-phenylmaleimide in good yield (Abdelhamid et al., 2000), Scheme 2.

The kinetic studies of pyrazoline formation from reaction of different chalcones with different compounds such as Schiff base, hydrazine, and thiourea in dimethylformamide and dimethylsulfoxide (DMSO) have been measured spectrophotometerically. The reaction is first order with respect to each reactant undergoes one or two steps to produce pyrazolines or pyrimidine thiones (Al-Khayat, 2010, Kaka et al., 2016). The kinetics of the reaction for the substituted chalcones have been also studied and found firstorder reaction (Upadhyay, 2007). 


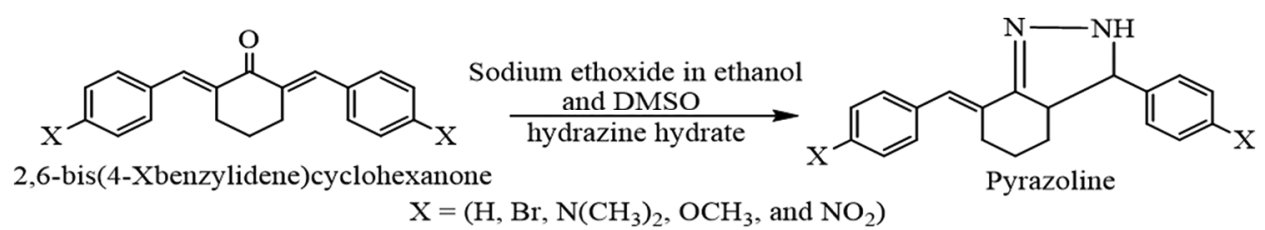

Scheme 1. Reaction pathway.

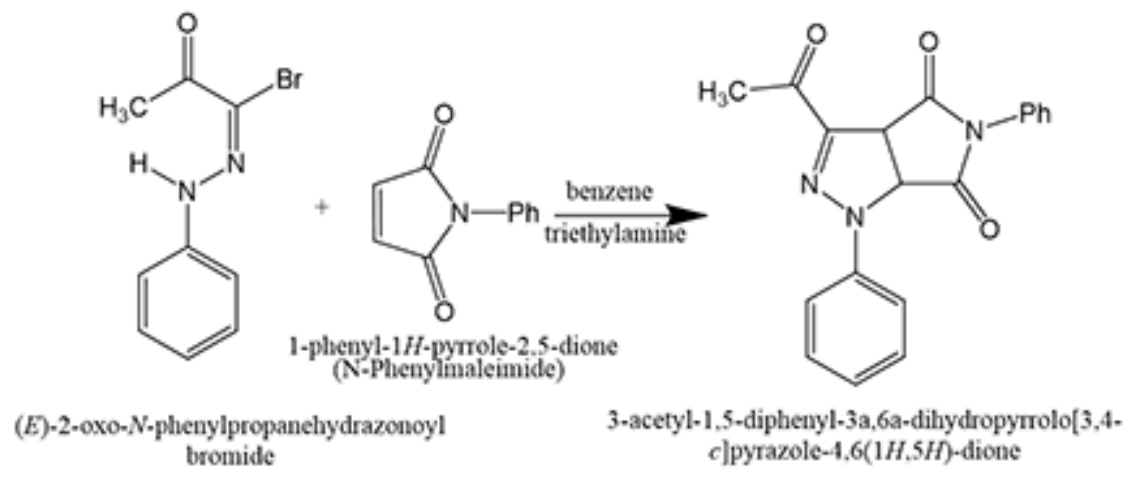

Scheme 2. Pyrazoine synthesis.

The present study is concerned with the kinetics of our synthesized pyrazolines and its derivatives. The effect of the electron configuration of substituents in para position of chalcones on the rate of chemical reaction and on the stability of activated compounds is studied. Moreover, the suitable mechanism for the reaction was suggested. Finally, the compensation effects for the substituent were observed and showed the expected routes.

\section{EXPERIMENTAL}

The infrared (IR) spectra $\left(\mathrm{KBr}, v \mathrm{~cm}^{-1}\right)$ for the synthesized compounds were measured using (Fourier-transform- IR [FT-IR]) spectrophotometer, and the ultraviolet (UV)visible spectra were estimated by Agilent Cary-100 (UVvisible Spectrophotometer). Nuclear magnetic resonance (NMR) spectra were showed on BRUKER $500.133 \mathrm{MHz}$ spectrometer (UK) using DMSO as a solvent.

\section{A. General Procedure}

Synthesis of (E)-7-benzylidene-3-phenyl-3,3a,4,5,6,7hexahydro-2H-indazole-2-carbothioamide and its derivatives:
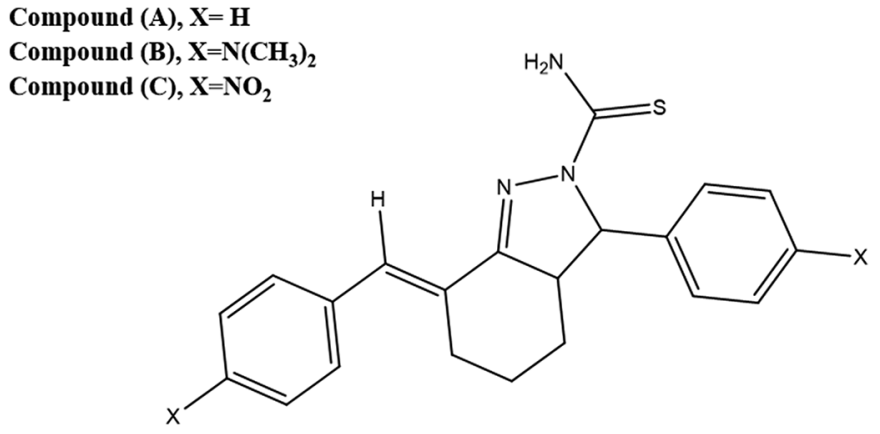

Thiosemicarbazide (4-mole eq.) was dissolved in absolute ethanol containing (10\% sodium ethoxide). It was then added to a stirred solution of 1-mole equation of 2 , 6-dibenzylidenecyclohexanone (Chalcone) or equivalent to one of its derivatives dissolved in $5 \mathrm{ml} \mathrm{DMSO}$. The reaction mixture was stirred for $24 \mathrm{~h}$ at room temperature and refluxed for another $24 \mathrm{~h}$. The reaction mixture was then cooled and poured into $10 \mathrm{ml}$ of ice water. The product was precipitated, washed twice with cold water to give the crude product, it was purified by recrystallization from ethanol to give pure product $(\mathrm{A}, \mathrm{B}$, and $\mathrm{C}),(67 \%, 63 \%$, and $77 \%$ yield), respectively.

For the purpose of kinetic study, the Agilent Cary-100 UVvisible spectrophotometer was used for scanning wavelength against absorbance to follow-up the absorbance change of the reactions at fixed wavelength. The spectrophotometer was supplied with the quartz cuvette type (Q) supported with Teflon quick fit stopper used for holding sample at constant temperature. The reaction temperature was controlled using an automatic thermostat type (Cary temperature controller) attached with circulating built-in pump to ensure a constant speed of circulating water. The supply company insulated all pipe connections properly so that temperature deviation inside the reaction cuvette was varied within the limits of $\pm 0.01^{\circ} \mathrm{C}$.

The rate of the reaction was determined by reaction between thiosemicarbazide and chalcones (A, B, and C) in DMSO and basic medium (sodium ethoxide) using absolute ethanol as a solvent.

For the purpose of zeroing at $\lambda_{\text {max }}(259.00) \mathrm{nm}$, chalcone $(0.002 \mathrm{mmol} / \mathrm{l}, 1 \mathrm{~mL})$, sodium ethoxide $10 \%(1 \mathrm{~mL})$, and $0.5 \mathrm{~mL}$ of each of the DMSO, ethanol solvents were mixed in quartz cell for both of the reaction and blank readings.

To study the reaction kinetic, thiosemicarbazide $(0.0001 \mathrm{mmol} / 1,1 \mathrm{~mL})$ was added to the reaction cell, and 
ethanol $(1 \mathrm{~mL})$ was added to the blank cell to reach the volume completion. The absorbance was monitored at different temperature. The decrease in the absorbance of thiosemicarbazide at $\lambda_{\max }(259.00) \mathrm{nm}$ in DMSO was occurred at different temperatures. The color changed from pale yellow to colorless gradually, due to the gradual consuming the thiosemicarbazide gradually, and converting to product.

The rates constant was evaluated by fitting the absorbance - time data to the appropriate pseudo first-order rate Equation-1 using linear regression program:

$$
\ln \left(\Lambda_{\mathrm{o}}-\Lambda_{\infty}\right) /\left(\Lambda_{\mathrm{t}}-\Lambda_{\infty}\right)=\mathrm{k}_{\text {obs. }} \mathrm{t}
$$

Where:

$\Lambda_{\mathrm{o}}=$ Absorbance of the thiosemicarbazide at time zero.

$\Lambda_{\mathrm{t}}=$ Absorbance of the thiosemicarbazide at different time.

$\Lambda_{\infty}=$ Absorbance of the thiosemicarbazide after reaction complete (when the absorbance became constant).

$\mathrm{k}_{\text {obs. }}=$ The rate constant for the pseudo first-order of the reaction.

$\mathrm{k}_{\text {obs. }}=\mathrm{k}$ [Thiosemicarbazide $]^{\mathrm{n}} ; \mathrm{n}=$ Order of the thiosemicarbazide as a pseudo first-order.

\section{Results AND Discussion}

Compounds $[\mathrm{A}, \mathrm{B}$, and $\mathrm{C}]$ were synthesized by the reaction of 1 mole equivalent of chalcones (Kaka, 2017) with 4 mole equivalents of thiosemicarbazide in DMSO and basic medium (sodium ethoxide) using absolute ethanol as a solvent, as shown in Scheme 3.

TABLE I

The IR Spectrum Assignment of the Compounds (A, B, And C)

\begin{tabular}{lccccc}
\hline \hline Compound $\mathrm{N}_{\text {str. }} \mathrm{v} / \mathrm{cm}^{-1}(\mathrm{~m})$ & $\begin{array}{c}\mathrm{C}=\mathrm{N}_{\text {str. }} \\
\mathrm{vcm}^{-1}(\mathrm{w})\end{array}$ & $\begin{array}{c}\mathrm{N}-\mathrm{H}_{\text {bend. }} \\
\mathrm{vcm}^{-1}(\mathrm{w})\end{array}$ & $\begin{array}{c}\mathrm{C}=\mathrm{C}_{\text {str. }} \text { Aromatic } \\
\mathrm{vcm}^{-1}(\mathrm{~m})\end{array}$ & $\begin{array}{c}\mathrm{N}-\mathrm{H} \text { wag } \\
\mathrm{v} / \mathrm{cm}^{-1}(\mathrm{~m})\end{array}$ \\
\hline $\mathrm{A}$ & 3338,3279 & 1650 & 1638 & 1625 & 748 \\
$\mathrm{~B}$ & 3408,33371 & 1694 & 1678 & 1603 & 770 \\
$\mathrm{C}$ & 3380,33359 & 1659 & 1635 & 1597 & 769 \\
\hline \hline
\end{tabular}

The structure of synthesized compounds was confirmed through a combination of various spectroscopic techniques including IR, UV-visible spectrophotometer, ${ }^{1} \mathrm{H}-\mathrm{NMR}$, and ${ }^{13} \mathrm{C}$ NMR spectra. The IR spectrum for the compound (A) showed two clear bands at 3338 and $3279 \mathrm{~cm}^{-1}$ corresponding to primary $\mathrm{NH}_{2}$ group, and a band at $1650 \mathrm{~cm}^{-1}$ which was corresponded to the $\mathrm{C}=\mathrm{N}$ stretching vibration. The $\mathrm{C}=\mathrm{C}$ group band was appeared at $1625 \mathrm{~cm}^{-1}$, whereas the $\mathrm{N}-\mathrm{H}$ bending vibration appeared near $1638 \mathrm{~cm}^{-1}$. The total characterization of IR bands for the compounds (A, B, and C) is shown in Table I.

The proton and carbon NMR of the compound (A, B, and C) is characterized in Table II.

The total characterization of proton and carbon NMR for the compounds (A) and its spectra is shown in the following pictorial Fig. 1.

Below ${ }^{1} \mathrm{H}-\mathrm{NMR}$ and ${ }^{13} \mathrm{C}-\mathrm{NMR}$ spectrum belongs to compound (A) Fig. 1:

In this study, the kinetic study of the formation of new pyrazoline compounds was conducted using UV-Visible spectroscopy by following the decrease in the absorbance of thiosemicarbazide $\left(\lambda_{\max } 259.00 \mathrm{~nm}\right)$. The band of the used thiosemicarbazide did not interfere with other spectral bands of chalcone and the product (pyrazoline). The decrease in absorbance of thiosemicarbazide is exactly equivalent to the remaining concentration of the reactant. Ethanol and DMSO were found to be suitable solvents for all the kinetic measurements. The reaction was found to be slow. Preliminary, attempts were made to find suitable concentration range of thiosemicarbazide, which obeys Beer's-Lambert law. A ratio of concentrations of (1:20) thiosemicarbazide: chalcones (or its derivatives) was found to be adequate and used in all our measurements. Table $\mathrm{V}$ shows $\lambda_{\max }$ of substituted thiosemicarbazide and chalcones, and the valid range of Beer-Lambert law. At first, a full scan of the reaction spectrum (between thiosemicarbazide and three different chalcones separately) was performed to

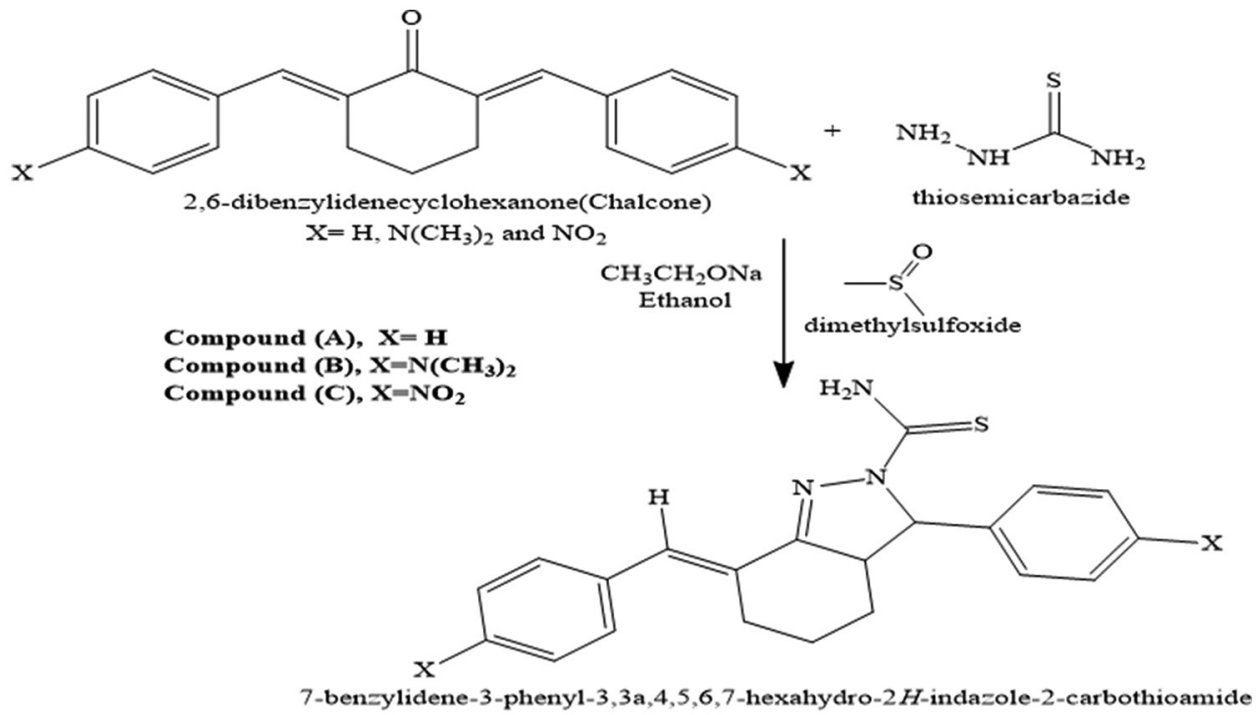

Scheme 3. Reaction pathway of pyrazoline synthesis. 
TABLE II

${ }^{1}$ H-NMR Chemical Shift Assignment in PPM of the Compounds(A, B, And C)

\begin{tabular}{|c|c|c|}
\hline Comp. & $\mathrm{X}$ & Chemical shifts in PPM \\
\hline $\mathrm{A}$ & $-\mathrm{H}$ & $\begin{array}{l}\text { 9.31 (2H, br.s, NH }), 7.49-7.26(8 \mathrm{H}, \mathrm{m}, \mathrm{Ar}-\mathrm{H}), 6.35(1 \mathrm{H}, \mathrm{m}, \mathrm{CH}=\mathrm{C}) \text {, } \\
3.92(1 \mathrm{H}, \mathrm{d}, \mathrm{CH}-\mathrm{N}), 2.46-2.45(1 \mathrm{H}, \mathrm{m}, \mathrm{CH}-\mathrm{C}=\mathrm{N}), 2.27-2.23 \\
(2 \mathrm{H}, \mathrm{m}, \mathrm{CH}-\mathrm{C}=\mathrm{CH}), 1.37-1.33\left(4 \mathrm{H}, \mathrm{m}, \mathrm{CH}_{2}-\mathrm{CH}_{2}\right) .\end{array}$ \\
\hline
\end{tabular}

TABLE III

${ }^{1} \mathrm{H}-\mathrm{NMR}$ FOR COMPOUND (A)

\begin{tabular}{lclc}
\hline \hline Proton & PPM & Multiplicity & Integration \\
\hline $\mathrm{H}_{12,13,15,16,17,18,20, \text { and } 21}$ & $7.49-7.26$ & $\mathrm{~d}$ & 8 \\
$\mathrm{H}_{23}$ & 6.35 & $\mathrm{~s}$ & 1 \\
$\mathrm{H}_{2}$ & $2.27-2.23$ & $\mathrm{~m}$ & 2 \\
$\mathrm{H}_{3}$ & $1.37-1.33$ & $\mathrm{~m}$ & 2 \\
$\mathrm{H}_{4}$ & $1.37-1.33$ & $\mathrm{~m}$ & 2 \\
$\mathrm{H}_{5}$ & 2.45 & $\mathrm{~m}$ & 1 \\
$\mathrm{H}_{8}$ & 3.92 & $\mathrm{~d}$ & 1 \\
$\mathrm{H}_{26}$ & 9.31 & br. s & 2 \\
\hline \hline
\end{tabular}

TABLE IV

${ }^{13} \mathrm{C}$-NMR FOR COMPOUNd (A)

\begin{tabular}{lc}
\hline \hline Carbon & PPM \\
\hline $\mathrm{C}_{12,13,15,16,17,18,20,21, \text { and } 23}$ & $141.6,135.6,130.3,128.2,124.3$ \\
$\mathrm{C}_{2}$ & 28.0 \\
$\mathrm{C}_{3}$ & 25.1 \\
$\mathrm{C}_{4}$ & 24.3 \\
$\mathrm{C}_{5}$ & 43.6 \\
$\mathrm{C}_{8}$ & 78.5 \\
$\mathrm{C}_{24}$ & 177.1 \\
\hline \hline
\end{tabular}

TABLE V

MaXimum AbSORption of Chalcones AND Pyrazolines in Dimethylsulfoxide

\begin{tabular}{llcl}
\hline \hline $\begin{array}{l}\lambda_{\max } \text { of } \\
\text { pyrazoline }\end{array}$ & Pyrazoline & $\begin{array}{c}\lambda_{\max } \text { of } \\
\text { chalcone }\end{array}$ & Compounds \\
\hline 344 & A & 350 & Chalcone $(\mathrm{p}-\mathrm{H})$ \\
349 & $\mathrm{~B}$ & 448 & Chalcone $\left(\mathrm{p}-\mathrm{N}\left(\mathrm{CH}_{3}\right)_{2}\right)$ \\
330 & $\mathrm{C}$ & 337 & Chalcone $\left(\mathrm{p}-\mathrm{NO}_{2}\right)$ \\
\hline \hline
\end{tabular}

choose a suitable wavelength for kinetic measurements, as shown in Fig. 2.

As we mentioned in the experimental part, after a $24 \mathrm{~h}$ of stirring and mixing of the reactants (thiosemicarbazide, sodium ethoxide, chalcone, and its derivatives) in DMSO, an appropriate absorption band of pyrazoline- $\mathrm{H}$ and its derivatives was built up systematically in the $344.00 \mathrm{~nm}$.

The figure below shows the decreases in absorbance of the thiosemicarbazide with no interference either with reactant or product or with no side reactions.

The rate of the disappearance of thiosemicarbazide is found to be sensitive to the temperature change in the range between $298.15 \mathrm{~K}$ and $318.15 \mathrm{~K}$. Therefore, the runs were carried out within this range of temperature.
In earlier study, theoretically, kinetic measurements of any bimolecular reaction are found totally second-order when 1:1 mixing mole ratio was used, which means first-order for each of reactants (Kaka, 2017).

Practically, the reaction showed first-order reaction for thiosemicarbazide, Equation 2.

To simplify our kinetic investigations and mathematical treatments of data, a pseudo first-order reaction was followed using large excess of chalcones (20-fold) compared to thiosemicarbazide concentration. In this case, the rate of reaction became:

$$
r=k_{\text {obs. }} \text { [Thiosemicarbazide] }
$$

Where $k_{\text {obs. }}=k$ [Chalcones] $]^{1}$, in this case, the thiosemicarbazide was found to be pseudo first-order of reaction. Plots of $\ln \frac{A_{o}-A_{\infty}}{A_{t}-A_{\infty}}$ versus time were always straight lines with slope that corresponds to $k_{o b s}$.

The above Equation (1) was applied for a mixture of thiosemicarbazide concentration of $2 \times 10^{-4} \mathrm{M}$ and large amount of chalcones (20-fold) $(0.004 \mathrm{M})$ for all of the reactions under study and lead to reasonable reaction rates even at different temperatures. Many runs were performed at different temperatures, and the measurements were always followed toward the completion of reaction. Typical plots show excellent fit to Equation (1) and were always linear, as shown in Fig. 3. Thus, the assumption of pseudo first-order reaction was fully proven.

The observed rate constant was calculated from the slope of the Equation (1). The standard deviation of the slope represented reasonable value of estimated rate constant $(\mathrm{K})$.

Plots of $\ln k_{\text {obs }}$ using data listed in Tables VI-VII versus the reciprocal absolute temperature between 298.15 and $318.15 \mathrm{~K}$ were drawn and found acceptable straight lines. The least-square method was used for plotting Arrhenius equations, and treating the mean rates constants at each temperature as a single point with a unit of weight.

The entropies of activation also gave good evidence about the shape of the activated complex and about the mechanistic pathway. The $\Delta \mathrm{S}^{\#}$ is estimated from the A-Factor, at $308.15 \mathrm{~K}$, according to the following Equation (3).

$$
\Delta \mathrm{S}^{\#}=\mathrm{R} \times \ln \mathrm{A} /\left(\left(\mathrm{e}^{2} \mathrm{kT}\right) / \mathrm{h}\right)
$$




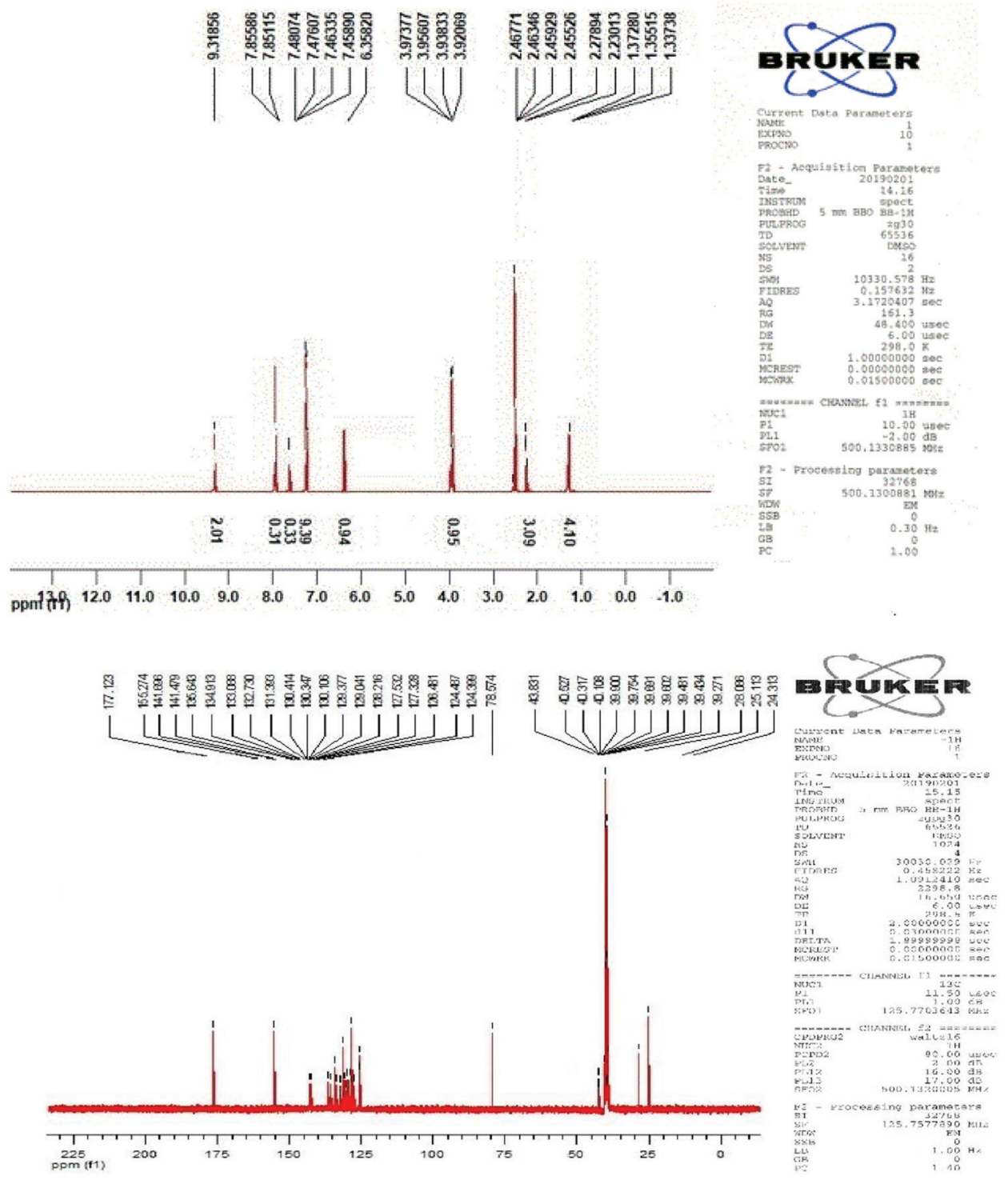

Fig. $1 .{ }^{1} \mathrm{H},{ }^{13} \mathrm{C}-\mathrm{NMR}$ spectrum for compound (A).

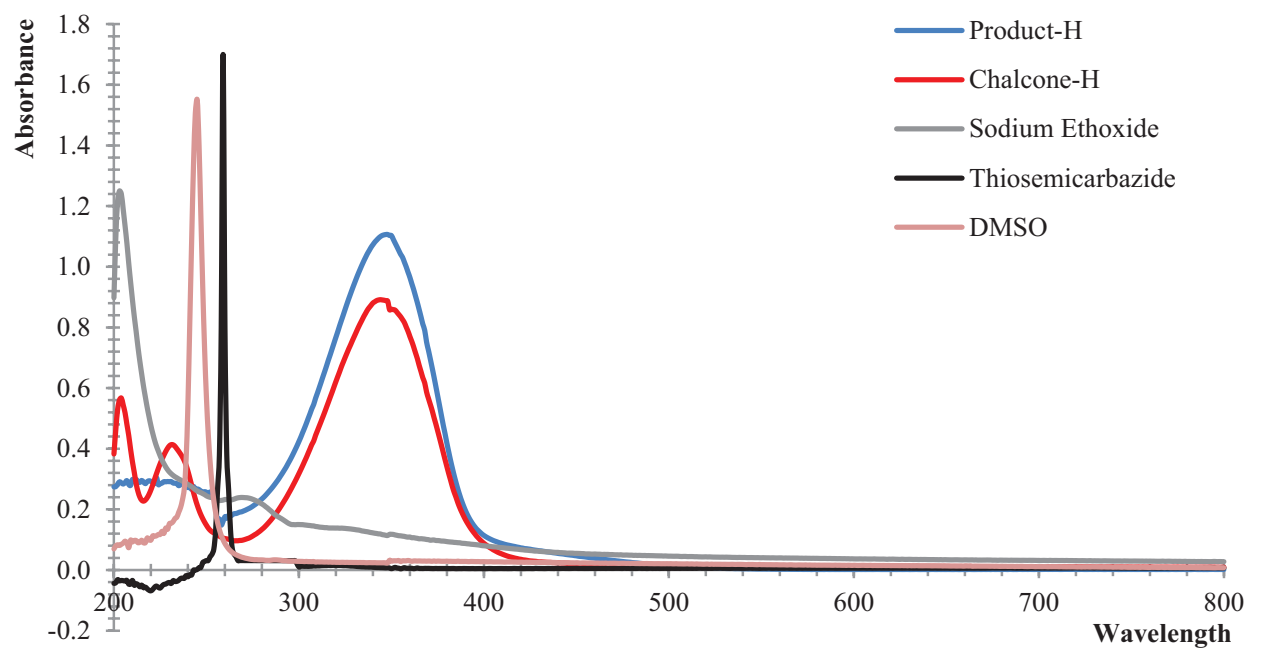

Fig. 2. Ultraviolet-visible spectrum for thiosemicarbazide, chalcones-H, sodium ethoxide, and product pyrazoline-H in dimethylsulfoxide (each one alone). 
A factor was calculated according to Arrhenius equation, as shown in Fig. 4, the intercept is $\mathrm{Ln} \mathrm{A}$.

$\Delta \mathrm{S} \#=$ Entropy of activation $\left(\mathrm{J} \mathrm{mol}^{-1} \mathrm{~K}^{-1}\right), \mathrm{R}=\mathrm{Gas}$ constant (8.314 J/mol. K).

$\mathrm{A}=$ Arrhenius factor was calculated from Intercept of Arrhenius equation $\mathrm{K}=\mathrm{A}$ e-E/RT. ((time)-1(Conc.)1-n) $\mathrm{n}=$ order of reaction, $\mathrm{e}=2.72, \mathrm{~K}=1.38 * 10-23 \mathrm{~m}^{2} \mathrm{~kg}^{\prime} \mathrm{s}-2 \mathrm{~K}-1$, $\mathrm{T}=$ Absolute temperature $(\mathrm{K}), \mathrm{h}=6.62 * 10-34 \mathrm{~m}^{2} \mathrm{~kg} / \mathrm{s}$.

The effect of substituted chalcones on the rate of the condensation process was studied. In the inspection of the effect of the electron-donating groups $\left(-\mathrm{N}\left(\mathrm{CH}_{3}\right)_{2}\right)$, we have noticed that these groups increase the electron density at the $\beta$-carbon of the $\mathrm{C}=\mathrm{C}$ of the chalcone (the reaction center), by conjugation. This can cause the reducing in the rate of reaction compared with the unsubstituted parent analogous. On the other hand, the electron withdrawing groups $\left(-\mathrm{NO}_{2}\right)$ decrease the availability of electrons at the $\beta$ - carbon of the $(\mathrm{C}=\mathrm{C})$ of the chalcone by conjugation, results in strengthening the attractive forces between reactants and enhancing the reaction rate. The difference in rates of reaction was found to be in the following order

$$
\underline{\mathrm{p}-\mathrm{NO}_{2}-\mathrm{p}-\mathrm{H}-\mathrm{p}-\mathrm{N}\left(\mathrm{CH}_{3}\right)_{2}}
$$

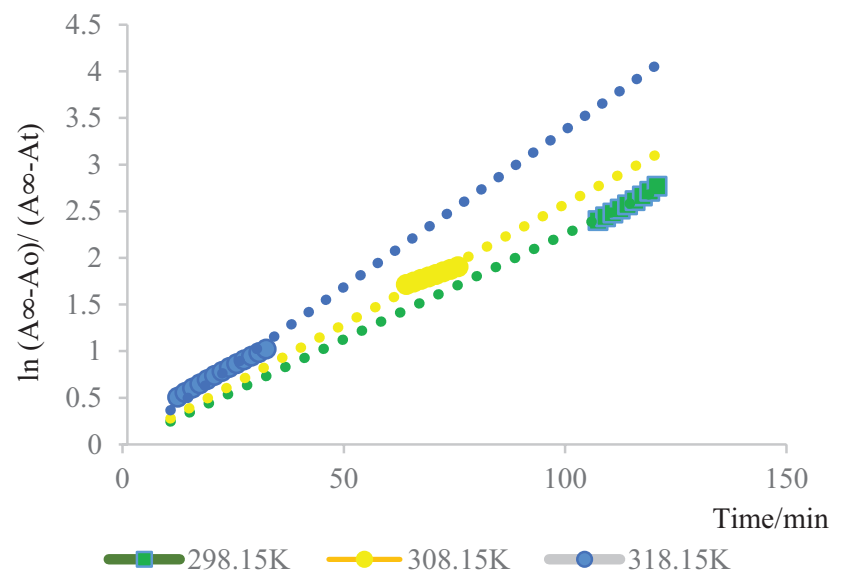

Fig. 3. Pseudo first-order plot for the reaction of chalcone-H with thiosemicarbazide (using sodium ethoxide) in dimethylsulfoxide at different temperatures.
Moving from left to right, the rate of the reaction increase of the observed reaction rates is shown in Fig. 5 and Tables VI-VII.

The values of activation parameters are of great importance to describe the mechanism under all circumstances studied here. The energies of activation for all reactants are generally small in value and vary within (26.897-4.781) $\mathrm{KJ} / \mathrm{mol}$. The variation of their values may be attributed to the electron-donating or withdrawing capabilities of the attacked groups.

Other important factors that control the reaction rate are the A-Factor and it $\Delta \mathrm{S}^{\#}$. These two factors are related to each other by the Equation (3), which is derived from the transition state theory (Ceylan and Gezegen, 2008). Using the above equation a value $\mathrm{A} \cong 10^{13.5} \mathrm{~s}^{-1}$ corresponds to $\Delta \mathrm{S}^{\#}=0$. The decrease in this value results in a negative entropies of activation. It is noticed that all of A-factors obtained for all the reactions under study are less than the above-mentioned value and correspondingly all the obtained $\Delta \mathrm{S}^{\#}$ values are negative.

The negative values of the $\Delta \mathrm{S}^{\#}$ of the reaction of all chalcones with thiosemicarbazide are shown in Tables VI-VII, indicate the formation of a restricted intermediate which suffers from lack of center degrees of freedom as compared to the reactants. The decrease in the value of A-factor provides an important indication about the stability of the intermediate and hence gives good support for explaining the reason for the differences in the value of rate constants. Since the decrease in the values of both $\mathrm{A}$-factor and $\Delta \mathrm{S}^{\#}$ leads to the same target. From these investigations, it can be concluded that the reaction of the chalcone with the thiosemicarbazide nucleophile proceeds through the formation of transition state in a relatively slow step. The rate constant values, the A-parameters values, the Gibbs free energy of activation (the reactions have the same mechanism route, as shown in Tables VI-VII), as well as the negative values of activation entropies are quite in agreement with the suggested mechanistic route. The reaction takes place according to Claisen route rather than Michael route depending on IR spectral data, which showed no

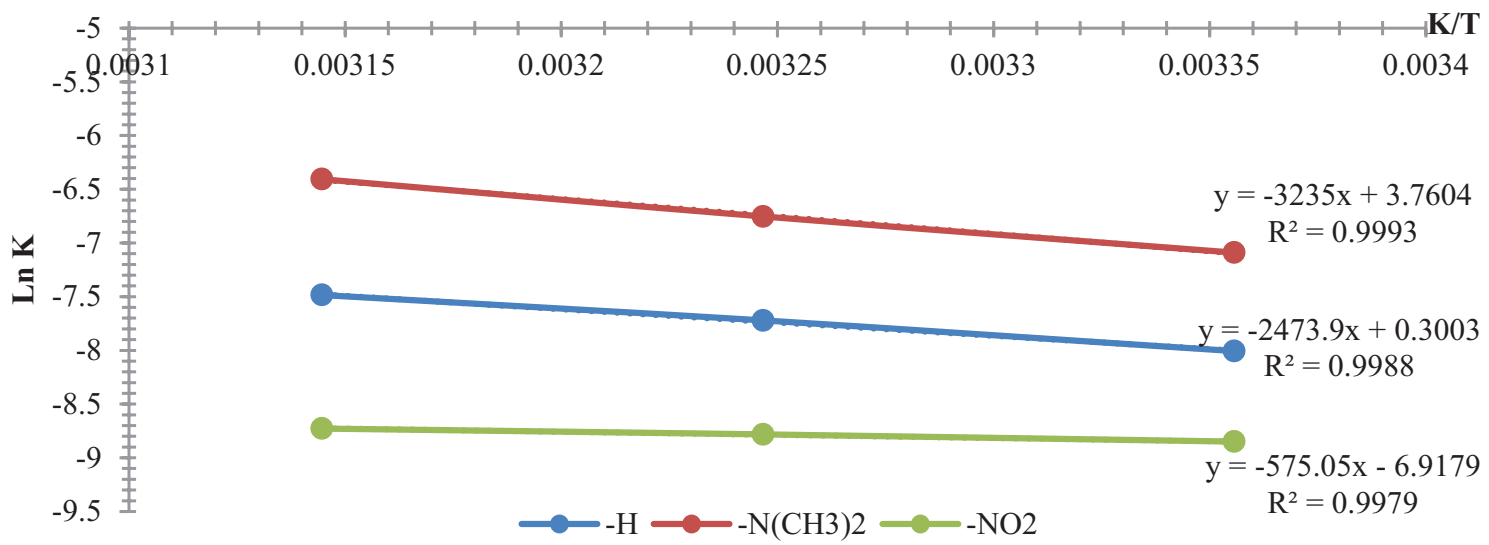

Fig. 4. Arrhenius plots for the reaction of compounds chalcones $\left(-\mathrm{H},-\mathrm{N}\left(\mathrm{CH}_{3}\right)_{2}\right.$ and $\left.-\mathrm{NO}_{2}\right)$ with thiosemicarbazide in dimethylsulfoxide as a solvent. 
peaks of N-H stretching of pyrazoline ring. In addition of that, ChemOffice 3D program theoretical calculations

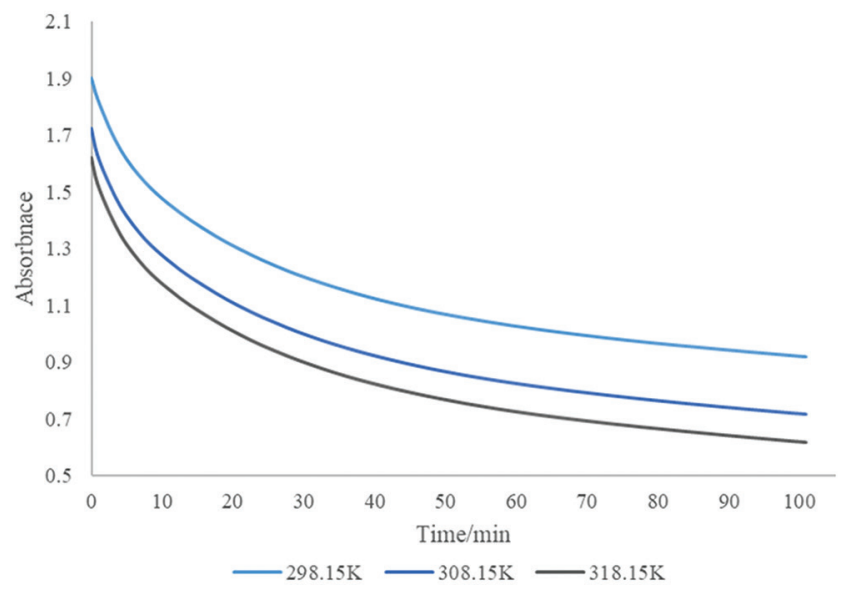

Fig. 5. Decrease in the concentration of thiosemicarbazide at different times and temperatures. found that the heat of formation (H. F.) of unsubstituted Claisen product equal to $131.8 \mathrm{kcal} / \mathrm{mol}$ which is less than Michael product equal to $228.8 \mathrm{kcal} / \mathrm{mol}$. This means the reaction goes through Claisen route because has less value of heat of formation. The mechanism of the reaction is shown in Scheme 5.

The kinetic study of the pyrazoline compounds (A, B, and $\mathrm{C}$ ) cannot fully explain the reaction mechanism; therefore, organic chemistry facts must be applied in combination with kinetic calculations.

To understand the certain mechanism of formation of all of the pyrazoline compounds (A, B, and C), true compensation effect was applied. It was noted that the compensation effect was a straight line for all substituent as shown in Fig. 6, which means all of the pyrazoline compounds (A, B, and C) forms according to the same route of mechanism. Moreover, the compensation effect also confirmed no effect of used solvents on the route of the mechanism (Fig. 6).

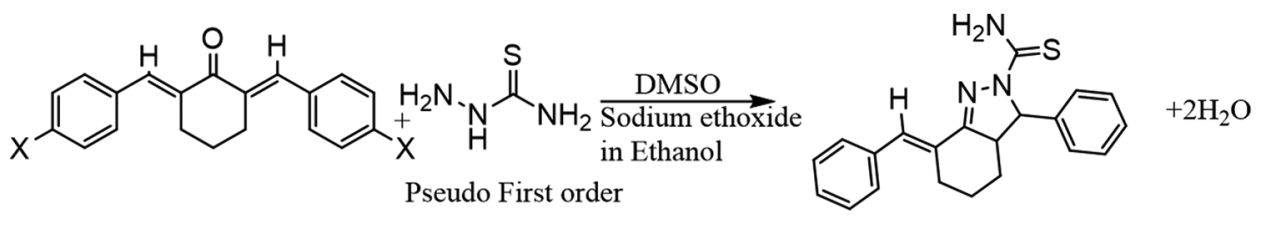

$\mathrm{X}=\mathrm{H}, \mathrm{N}\left(\mathrm{CH}_{3}\right)_{2}, \mathrm{NO}_{2}$

Scheme 4. Reaction pathway of payrazoline.

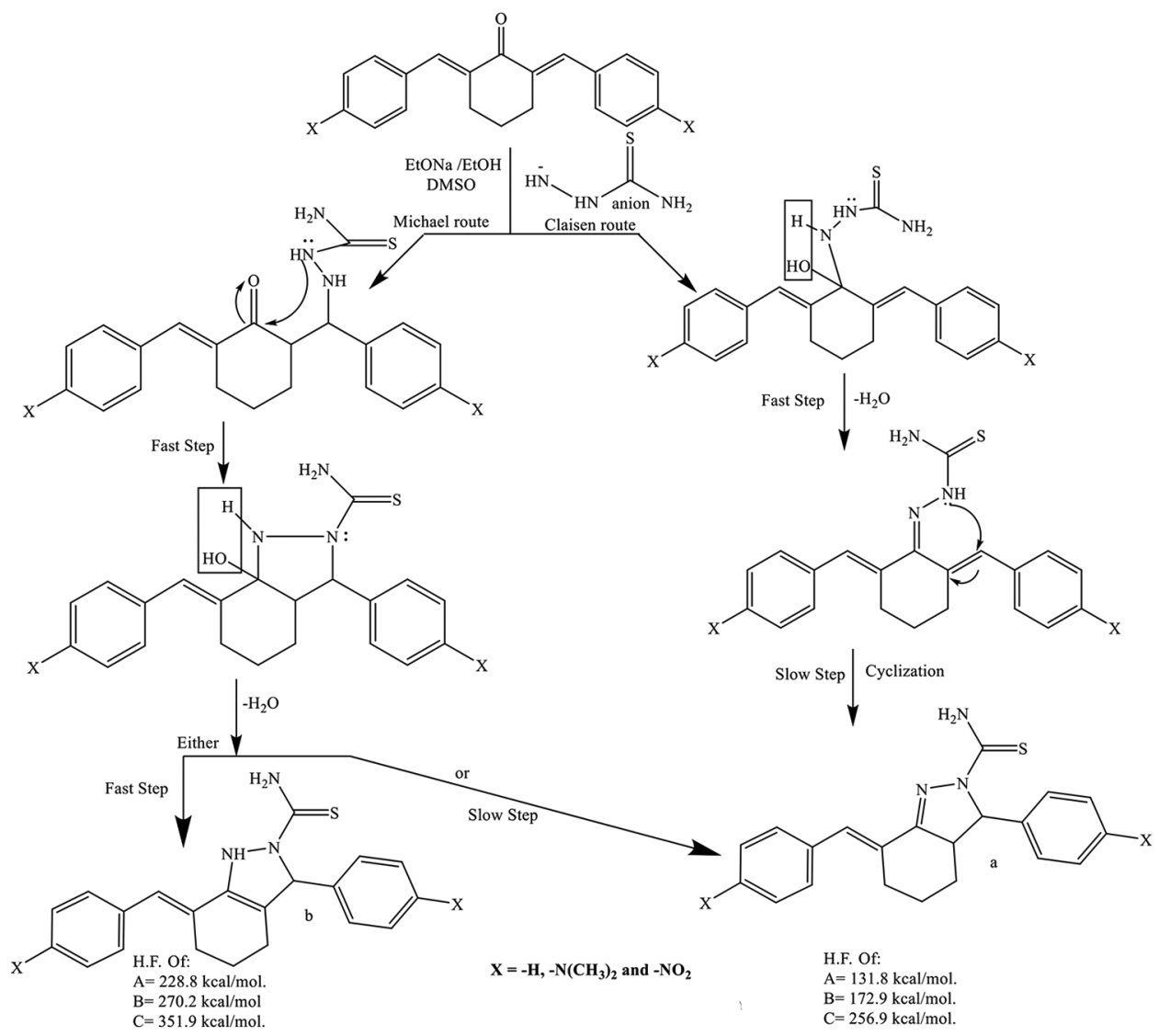

Scheme 5. Proposed reaction mechanism. 
TABLE VI

Observed Rate Constants, for the Reaction Chalcone-H with Thiosemicarbazide, Obtained from Kinetic Plots at Different

\begin{tabular}{|c|c|c|c|c|c|c|c|c|}
\hline $\mathrm{T} / \mathrm{K}$ & $\mathrm{K}(\mathrm{s}) / 10^{4} \mathrm{~s}^{-1}$ & $\mathrm{t} 1 / 2 / 10^{-2} \mathrm{~s}$ & $\mathrm{E} / \mathrm{KJmol}^{-1}$ & $\Delta \mathrm{S}^{\#} / \mathrm{JK}^{-1} \mathrm{~mol}^{-1}$ & $\Delta \mathrm{G}^{\#} / \mathrm{KJ} \mathrm{mol}^{-1}$ & $\mathrm{~A} / 10^{-4}$ & $\mathrm{R}^{2}$ & $\mathrm{SD} / 10^{4}$ \\
\hline 298.15 & 1.435 & 48.293 & 4.781 & -311.019 & 100.621 & 9.899 & 0.9885 & 0.038 \\
\hline 308.15 & 1.535 & 45.147 & & & & & 0.9900 & 0.058 \\
\hline 318.15 & 1.620 & 42.778 & & & & & 0.9900 & 0.078 \\
\hline
\end{tabular}

TABLE VII

Observed Rate Constants, for the Reaction Chalcone-N $\left(\mathrm{CH}_{3}\right)_{2}$ with Thiosemicarbazide, Obtained from Kinetic Plots at Different Temperatures

\begin{tabular}{lcccccrr}
\hline \hline $\mathrm{T} / \mathrm{K}$ & $\mathrm{K}(\mathrm{s}) / 10^{4} \mathrm{~s}^{-1}$ & $\mathrm{t} 1 / 2 / 10^{-2} \mathrm{~s}$ & $\mathrm{E} / \mathrm{KJ} \mathrm{mol}^{-1}$ & $\Delta \mathrm{S}^{\#} / \mathrm{JK}^{-1} \mathrm{~mol}^{-1}$ & $\Delta \mathrm{G}^{\#} / \mathrm{KJ} \mathrm{mol}^{-1}$ & $\mathrm{~A} / \mathrm{s}^{-1}$ & \multicolumn{1}{c}{$\mathrm{R}^{2}$} \\
\hline 298.15 & 3.333 & 20.790 & 20.568 & -251.007 & 97.916 & 0.9911 & 0.053 \\
308.15 & 4.433 & 15.632 & & & & 0.9800 & 0.025 \\
318.15 & 5.622 & 12.338 & & & & 0.9900 & 0.044 \\
\hline \hline
\end{tabular}

TABLE VIII

Observed Rate Constants, for the Reaction Chalcone-NO $\mathrm{N}_{2}$ with Thiosemicarbazide, Obtained from Kinetic Plots at Different

\begin{tabular}{|c|c|c|c|c|c|c|c|c|}
\hline $\mathrm{T} / \mathrm{K}$ & $\mathrm{K}(\mathrm{s}) / 10^{4} \mathrm{~s}^{-1}$ & $\mathrm{t} 1 / 2 / 10^{-2} \mathrm{~s}$ & $\mathrm{E} / \mathrm{KJ} \mathrm{mol}^{-1}$ & $\Delta \mathrm{S}^{\#} / \mathrm{JK}^{-1} \mathrm{~mol}^{-1}$ & $\Delta \mathrm{G}^{\#} / \mathrm{kJ} \mathrm{mol}^{-1}$ & $\mathrm{~A} / 10^{1} \mathrm{~s}^{-1}$ & $\mathrm{R}^{2}$ & $\mathrm{SD} / 10^{4}$ \\
\hline 298.15 & 8.330 & 8.316 & 26.897 & -222.240 & 95.379 & 4.297 & 0.9993 & 0.017 \\
\hline 308.15 & 11.670 & 5.940 & & & & & 0.9940 & 0.089 \\
\hline 318.15 & 16.500 & 4.200 & & & & & 0.9911 & 0.048 \\
\hline
\end{tabular}

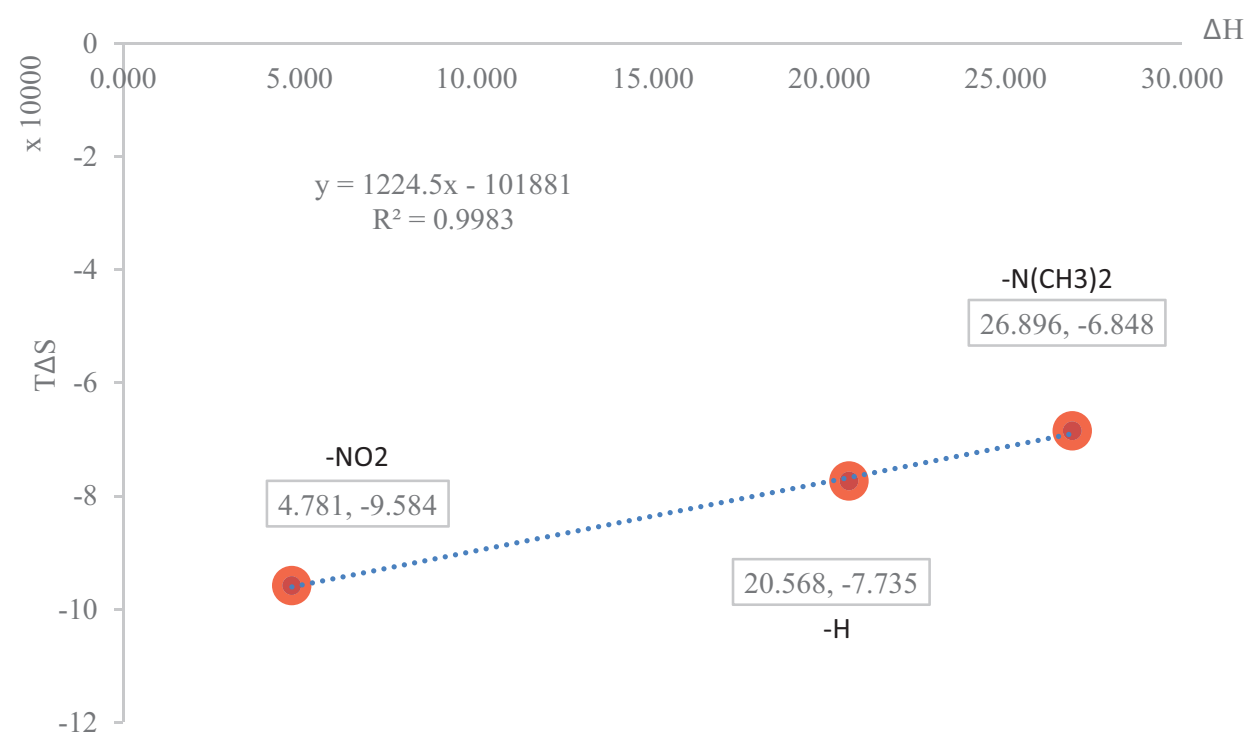

Fig. 6. Compensation effect for the (A, B, and C) compounds.

\section{CONCLUSIONS}

A series of novel pyrazoline compounds (A, B, and C) were synthesized successfully and fully characterized using UV-Vis, ${ }^{1} \mathrm{H}-\mathrm{NMR},{ }^{13} \mathrm{C}-\mathrm{NMR}$, and FT-IR spectroscopy. The kinetic study showed first-order reaction of thiosemicarbazide with chalcones to form pyrazoline compounds (A, B, and C). The substituents affected the rate of the reaction according to the following sequence. The highest rate of the reaction is found for the electrondonating group $\left(\mathrm{N}\left(\mathrm{CH}_{3}\right)_{2}\right.$, and the lowest for the electron withdrawing group $\left(\mathrm{NO}_{2}\right)$.

$$
\mathrm{p}-\mathrm{NO}_{2}-\mathrm{p}-\mathrm{H}-\mathrm{p}-\mathrm{N}\left(\mathrm{CH}_{3}\right)_{2}
$$

It is also concluded that the low values of Arrhenius factor and correspondingly the negative values of $\Delta S^{\#}$ activation provided support to the restricted transition state, which is, demand some degrees of freedom in slow step of the reaction.

The relative constancy of $\Delta \mathrm{G}^{\#}$ of activation values and compensation effect indicated that the reaction of all the substituted chalcones and its derivatives have the same reaction mechanism (Kaka, 2017), it is proposed that the reaction takes place according to Claisen route rather than Michael route based on IR spectral data, which showed no peaks of $\mathrm{N}-\mathrm{H}$ stretching of pyrazoline ring which is expected to appear if the reaction goes through Michael route. Moreover, the heat of formation of Claisen product is less than Michael product based on ChemOffice 3D program calculations. 


\section{ACKNOWLEDGMENT}

We are greatly indebted to Koya University, Faculty of Science and Health, Chemistry Department, for many helps and providing facilities that made this work possible.

\section{REFERENCES}

Abdelhamid, A., Zohdi, H., Sallam, M., and Ahmed, N. 2000. Reactions with hydrazonoyl halides. 31 . Synthesis of some new pyrrolidino [3, 4-c] pyrazolines, pyrazoles, and pyrazolo [3, 4-d] pyridazines. Molecules, 5, pp.967-973.

AL-Khayat, R.Z. 2010. PhD Thesis. University of Mosul.

Beyhan, N., Kocyigit-Kaymakcioglu, B., Gümrü, S., and Aricioglu, F. 2017. Synthesis and anticonvulsant activity of some 2-pyrazolines derived from chalcones. Arabian Journal of Chemistry, 10, pp.S2073-S2081.

Carey, F. 1996. Organic chemistry. McGraw-HiIl, New York, p.749.

Ceylan, M., and Gezegen, H. 2008. Preparation of 1, 5-diketones by addition of cyclohexanone to chalcones under solvent-free phase transfer catalyst condition. Turkish Journal of Chemistry, 32, pp.55-61.

Ebenezer, W., and Wight, P. 1995. In: Katrizky, A.R., Meth-Cohn, O., and Ress, C.W., editors. Comprehensive organic function group transfoamation. Vol. 3. Pergmon Press, Oxford, p.206.

Esmaeel, D.M.T. 1988. Organic chemistry. Directors are Publishing Houses, Mosul.

Ethiraj, K., Nithya, P., Krishnakumar, V., Mathew, A.J., and Khan, F.N. 2013. Synthesis and cytotoxicity study of pyrazoline derivatives of methoxy substituted naphthyl chalcones. Research on Chemical Intermediates, 39, pp.1833-1841.

Fazaeli, R., Aliyan, H., Bordbar, M., and Mohammadi, E. 2010. H3PW12O40: Highly efficient catalysts for the synthesis of novel 1,3,5-triaryl-2-pyrazoline derivatives. Open Catalysis Journal, 3, pp.79-82.

Gutsche, C.D. 1967. Chemistry of carbonyl compounds. Prentice-Hall, New Jersey.

Hamad, W.M., Kaka, K.N. Al-Hamadany, A.J., and Dabbagh, A.M. 2016. Synthesis and spectral characterization of some fused pyrimidine thiones. Journal Of Raparin University, 3, p.87.

Hassan, S.Y. 2011. Synthesis and biological activity of some new pyrazoline and pyrimidine derivatives. Journal of the Brazilian Chemical Society, 22, pp.1286-1298.

Joshi, V.D., Kshirsagar, M.D., and Sarita, S. 2012. Synthesis and antimicrobial activities of various pyrazolines from chalcones. International Journal of ChemTech Research, 4, pp.971-975.
Kaka, K., Dabbagh, A., and Hamad, W. 2016. Kinetics Study of the Formation of Pyrmidine Thione from the Reaction of 2, 6-Dibenzylidinecyclohexanone and its derivatives with Thiourea. ARO The Scientific Journal of Koya University, 4, pp.37-42.

Kaka, K.N. 2017. Kinetics and Mechanistics Studies on the Formation of 2,6-dibenzylidinecyclohexanones and their Reactions with Bromine, Hydrazine and Thiourea. Ph.D, Mosul.

Kendre, M., and Baseer, M. 2013. Synthesis and evaluation of some new pyrazoline derivatives as antimicrobial agents. Oriental Journal Chemistry, 29, pp. 253-256.

Lévai, A. 2005. Synthesis of chlorinated 3, 5-diaryl-2-pyrazolines by the reaction of chlorochalcones with hydrazines. Arkivoc, 9, pp.344-352.

Li, J.T., Zhang, X.H., and Lin, Z.P. 2007. An improved synthesis of 1, 3, 5-triaryl2-pyrazolines in acetic acid aqueous solution under ultrasound irradiation. Beilstein Journal of Organic Chemistry, 3, p.13.

Mccrae, W. 1973. Basic organic reactions. Heyden and Son Ltd., London.

Monga, V., Goyal, K., Steindel, M., Malhotra, M., Rajani, D.P., and Rajani, S.D. 2014. Synthesis and evaluation of new chalcones, derived pyrazoline and cyclohexenone derivatives as potent antimicrobial, antitubercular and antileishmanial agents. Medicinal Chemistry Research, 23, pp.2019-2032.

Pandya, M., Kapadiya, K., Pandit, C., and Purohit, D. 2017. Synthesis of halogenated chalcones, pyrazolines and microbial evaluation of derived scaffolds. Journal of Scientific and Industrial Research, 76, pp.173-178.

Patel, M., Dodiya, B., Ghetiya, R., Joshi, K., Vekariya, P., Bapodara, A., and Joshi, H. 2011. Synthesis and antimicrobial evaluation of pyrazoline derivatives. International Journal ChemTech Research, 3, pp.967-974.

Powers, D.G., Casebier, D.S., Fokas, D., Ryan, W.J., Troth, J.R., and Coffen, D.L. 1998. Automated parallel synthesis of chalcone-based screening libraries. Tetrahedron, 54, pp.4085-4096.

Qiu, H., Sarkar, S.M., Lee, D.H., and Jin, M.J. 2008. Highly effective silica gel-supported N-heterocyclic carbene Pd catalyst for suzuki miyaura coupling reaction. Green Chemistry, 10, pp.37-40.

Ramage, G., Rodd, E., and Landquist, J. 1957. XVI. Chemistry of carbon compounds. IVC, heterocyclic compounds. Elsevier, New York.

Sloop, J.C., Lechner, B., Washington, G., Bumgardner, C.L., Loehle, W.D., and Creasy, W. 2008. Pyrazole formation: Examination of kinetics, substituent effects, and mechanistic pathways. International Journal of Chemical Kinetics, 40, pp.370-383.

Upadhyay, S.K. 2007. Chemical kinetics and reaction dynamics. Springer Science and Business Media, Berlin. 